\title{
Prevalence and Factors Related to Physical and Sexual Violence Among Female Technical School Students of Dilla, SNNPR, Ethiopia
}

\author{
Girma Worku Obsie ${ }^{1, *}$, Zeleke Girma Abeta ${ }^{2}$ \\ ${ }^{1}$ Department of Public Health College of Health Science, Arsi University, Asella, Ethiopia \\ ${ }^{2}$ Department of Public Health College of Medical and Health Science, Dilla University, Dilla, Ethiopia \\ Email address: \\ natigirmaw16@gamil.com (G. W. Obsie),zelekegirma4@gamil.com (Z. G. Abeta) \\ ${ }^{*}$ Corresponding author
}

To cite this article:

Girma Worku Obsie, Zeleke Girma Abeta. Prevalence and Factors Related to Physical and Sexual Violence Among Female Technical School Students of Dilla, Snnpr, Ethiopia. International Journal of Elementary Education. Vol. 10, No. 1, 2021, pp. 21-25.

doi: 10.11648/j.ijeedu.20211001.13

Received: December 8, 2020; Accepted: January 12, 2021; Published: March 13, 2021

\begin{abstract}
Violence against women, is directly stated as gender-centered violence, these days commonly known as a serious human rights abuse, and gradually also as a significant public health problem that concerns of all services providing of society. Objective: The aim of the study was to determine the prevalence and Associated factors of sexual and physical violence among female technical school students in Dilla, South Nation Nationalities Peoples Region, Ethiopia in 2018. Methods: A cross sectional study was carried out an institution based survey using self-administered anonymous questionnaire among randomly selected 167 female students. Both binary and multivariate logistic regression were used to identify associated between dependent and independents variables at p-value less than 0.05 with $95 \%$ confidence intervals. Result: From study participants those who had not sexual partner (Adjusted Odd Ratio) AOR = 3.61, 95\%CI: 1.8-14.7), having parents not living together $(\mathrm{AOR}=1.93,95 \% \mathrm{CI}: 1.54-3.26)$ and age group between $18-22$ years $(\mathrm{AOR}=2.62,95 \% \mathrm{CI}: 1.05-6.81)$ were significantly associated with physically violated whereas no family support $(\mathrm{AOR}=2.75,95 \% \mathrm{CI}: 1.67-5.34)$ and no married $(\mathrm{AOR}=3.32$, 95\%CI: 1.21-9.13) were significantly associated with sexually violated in this academic year. Conclusion: The findings of this study showed that sexual and physical violence are serious and prevailing problems among study subjects of Technical school. It is recommended that sexual and physical violence deserve need remedial action from policy makers, schools, parents, students and other concerning stakeholders are working on social works.
\end{abstract}

Keywords: Physical and Sexual Violence, Prevalence, Associated Factors, Technical Students, Ethiopia

\section{Introduction}

Till today, most governments and policy-makers imaged that violence against women kept as trend culture of society and restricted to protect a number of women against of the problems. The social welfare and justice systems were try to talked outlook of the cases of violence in the early. But the collective efforts of grass- roots and international women's officialdoms, intercontinental professionals, and devoted administrations have occasioned in a philosophical revolution in public awareness concerning this subject [1].

Violence against women, is directly stated as gendercentered violence, these days commonly known as a serious human rights abuse, and gradually also as a significant public health problem that concerns of all services providing of society [2, 3].

Any action of gender-based violence that consequences in, physical, sexual or psychological were violence against women. Thus its outcomes suffering to women, comprising threats of coercion or arbitrary scarcities of freedom, whether taking place in public or private life [4].

Those involving sexual, psychological, and physical act that exercising of wife beating, burning, and acid throwing; whereas sexual abuse is addressing via rape, and incest by family members. Other acts such as female genital cutting, female feticide and infanticide are also main sexual abuse 
[5].

In Ethiopia, there are a few studies regarding violence on female technical school students. It is relevant to look into the problem so as to have to the basic information which will help policy makers and organizations working with youth to design appropriate measures. Expansion female education at all levels has given especially emphasis by the government of Ethiopia. This effort can contribute a lot in promoting gender equality if implemented successfully [6].

In areas where gender based violence is common, it is very difficult for girls to continue their education as desired, and even dropping out can occur. Gender based violence can affect the health and welfare of adolescents negatively and the risk of sexually transmitted infections including HIV/AIDS, and unwanted pregnancies compounds the problem. In order to take appropriate public health measures by responsible agents to prevent gender based violence and create conducive environment for women and girl students in particular, the need for scientific studies on prevalence and risk factors for gender based violence has paramount importance. It is also a timely issue because this problem is gaining prominence worldwide and documenting it systematically will help in designing appropriate measures. With the current consensus on the issue of female empowerment as a key to development, the results of this study are useful for political as well as public health decision making [6]. Therefore, this study is aimed to describe magnitude of sexual and physical violence, and related risk factors among female technical school students.

\section{Methods and Materials}

\subsection{Study Area and Design}

Institutional based cross-sectional was done in April 2018 in Dilla Town that is located in Gedeo Zone of Southern People Nation Nationalities Regional Government and $365 \mathrm{kms}$ south of Addis Ababa. The Town has only one technical school and one Government University. The rural kebeles are surrounding the town cultivate incents and coffee vastly.

\subsection{Population and Sample Size Determination}

All female technical school students of Dilla Town were source of population. The study considered $13.2 \%$ prevalence of complete rape obtained from previous study conducted on high school students in Dilla Town, southern Ethiopia, in March 2007 at $95 \%$ certainty and maximum discrepancy of $5 \%$ between the sample and source population. An additional 10 percent was added as a contingency in order to compensate possible non respondents. By doing so, a total of 167 female students were involved in the study.

\subsection{Sampling Procedures}

The study was conducted in Simple Random Sampling technique to select study students from each level proportional to their population size using random table generation adjusted in SPSS.

\subsection{Data Collection Tools and Procedures}

Structure self-administer questionnaires were prepared in English that adopted from WHO Multi-Country study on women's health and domestic violence was used with some modification. The questionnaires were with component of socio-demographic characteristics and others variables. Two diploma nurses were assigned for facilitation of data collection and training was given for facilitators and supervisors before conducted data collected.

\subsection{Data Analysis}

The collected data were entered, into Epi info version 7, then exported to SPSS version 20 for cleaning and analysis. Descriptive statistics were calculated to describe frequencies and percent of data. Both binary and multivariable logistic regression analysis were applied to determine the presence of statistically significant association between dependent and independents variables. Considering an adjusted odd ratio with $95 \% \mathrm{CI}$ were calculated at P-value less than 0.05 was stated as statistically significant.

\subsection{Operational Definition}

Sexual violence: It includes sexual harassment, performed rape and attempted rape

Sexual harassment_is unwanted sexual behavior such as physical contacts or verbal comments, jokes, questions, and suggestions.

Rape_ Is the act of forcing a female student through violent threats and deception to engage in sexual behavior with penetration of the vagina.

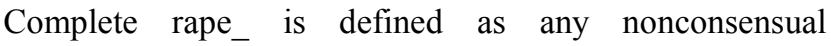
penetration of the vagina by Physical or by threatening of body harm, or when the victim is incapable of giving consent

Attempted rape _ is defined as a trial to have sexual intercourse without consent of the girl but without penetration of the vagina

physical violence _ It includes sexual harassment, performed rape and attempted rape slapped, pushed, or shoved, hit with a fist, kicked, dragged, and threatened with a weapon.

\section{Results}

A total of 167 female technical school students were involved in the study which was $100 \%$ response rate. Those within the age range of $18-22$ were 123 (73.7\%). Among the total more than one-third $(31.7 \%)$ of students were level I, $26.9 \%$ were Level II, 22.2\% were level III and 19.2\% were level IV. The predominant religion was protestant $(38.6 \%)$ followed by orthodox (29.5\%). Fifteen (9\%) and greater than half 94 (56.3\%) of students were reported was married and have a male partner. Out of the total students $87(55.1 \%)$ were in rural areas until the age of 12 years. Seventy-three (43.6\%) of students reported that they did not live close to their parents. (Table 1) 
Table 1. Socio demographic characteristics of Dilla technical school female Students in Dila, SNNRP, Ethiopia April 2018 (n=167).

\begin{tabular}{ll}
\hline Variable (n=167) & Frequency (\%) \\
\hline Age & $123(73.7 \%)$ \\
$18-22$ & $44(26.3 \%)$ \\
$>23$ & $49(29.5 \%)$ \\
Religious & $30(18.1 \%)$ \\
Orthodox & $64(38.6 \%)$ \\
Muslim & $24(13.9 \%)$ \\
Protestant & \\
Catholic & $53(31.7 \%)$ \\
Level of education & $45(26.9 \%)$ \\
Level I & $37(22.2 \%)$ \\
Level II & $32(19.2 \%)$ \\
Level III & \\
Level IV & $94(56.3 \%)$ \\
Marital status & $58(34.7 \%)$ \\
Has male partner & \\
NO/single & $80(47.9 \%)$ \\
Childhood residence & $87(52.1 \%)$ \\
Urban & \\
Rural & $94(56.2 \%)$ \\
Live close to family & $73(43.8 \%)$ \\
Yes & $130(77.8 \%)$ \\
NO & $37(22.2 \%)$ \\
Can get family support & Yes \\
No &
\end{tabular}

Reasons reported to have first sexual intercourse was 35 $(24.6 \%)$ case of marriage, $24(16.9 \%)$, no case of marriage but desired to have sex, $15(10.6 \%)$ being forced, and 13 $(9.2 \%)$ case of peer pressure.

\subsection{Proportion of Physical and Sexual Violence}

A total of 167 students completed the received questionnaire about their experiences of physical and sexual violence and more than half $93(55.68 \%)$ and nearly threefourth $117(70.05 \%)$ of respondents reported that they faced physical violence before they join technical school and during the current academic year. Sixty-seven (40.6\%) of those who experienced physical violence at some time in their lives reported that they didn't tell about the violence to anybody. The prevalence of specific acts of physical violence in current academic year was reported that $65.86 \%$ for slapping, $70.05 \%$ pushed, $50.89 \%$ beat with fist (hitting), $25.14 \%$ kicked and $11.97 \%$ threatened using weapon. Out of the total students nearly three-quarter $120(71.85 \%)$ had experienced sexual violence at some time in their lives.

One hundred ninety $(71.25 \%)$ experienced sexual violence before joining technical school where as above two-third 115 $(68.86 \%)$ of respondents during current academic year. Of the total of respondents, greater than half $93(55.7 \%)$ reported being a victim of performed rape after joining technical school and attempted rape was reported by $119(71.3 \%)$ of female students after joining technical school. (Table 2)

Table 2. History of physical and sexual violence before joining technical school, and during the current academic year among female students, Dilla Technical school, April $2018(n=167)$.

\begin{tabular}{lll}
\hline Violence Status & Before joining technical school (\#\%) & After joining technical school (\#\%) \\
\hline Acts of physical violence & & \\
Slapped & $65(38.9)$ & $110(65.9)$ \\
Pushed & $89(53.3)$ & $117(70.1)$ \\
Beat with first & $93(55.7)$ & $89(50.9)$ \\
Kicked & $41(24.6)$ & $42(25.1)$ \\
Choked/ burned & $42(25.1)$ & $18(10.8)$ \\
Use of weapon & $17(10.2)$ & $20(12)$ \\
Acts of sexual violence & & $93(55.7)$ \\
Performed rape & $86(51.8)$ & $119(71.3)$ \\
Attempted rape & $115(68.9)$ & $104(62.3)$ \\
Sexual harassment & $54(32.3)$ & \\
\hline
\end{tabular}

\subsection{Factors Related to Physical and Sexual Violence}

By using backward stepwise multivariate logistic regression age group, education level, Parents live together and currently married/have partner significant association with physical and sexual violence. Respondents who were their age between 18-22 years more than two times ever had physical violence compared with others age groups $(\mathrm{P}=0.03)$. 
Those who were education level I about three times more likely to physical violence compare to their education level IV $(\mathrm{P}=0.025)$. Respondents those had no partners more than three times ever had sexual violence compared to married
$(\mathrm{P}=0.002)$. Respondents who were no parents live together more than two times risky to sexual violence compared to their parents live together at all $(\mathrm{P}=0.004)$

Table 3. Bivariate and multivariate analyses for physical and sexual violence in this academic year among technical school female students Dilla Town, April 2018. $(n=167)$.

\begin{tabular}{|c|c|c|c|c|c|c|c|c|}
\hline \multirow{2}{*}{ Variables } & \multicolumn{2}{|c|}{ Physical Violence } & \multirow{2}{*}{ COR $(95 \%$ CI) } & \multirow{2}{*}{ AOR $(95 \% C l)$} & \multicolumn{2}{|c|}{ Sexual Violence } & \multirow{2}{*}{ COR $(95 \% C I)$} & \multirow{2}{*}{ AOR $(95 \% C I)$} \\
\hline & Yes & No & & & Yes & No & & \\
\hline \multicolumn{9}{|l|}{ Age (yr) } \\
\hline$>=23$ & 23 & 44 & 1 & 1 & 33 & 34 & 1 & 1 \\
\hline $18-22$ & 70 & 13 & $2.7(1.45-4.9)^{*}$ & $2.6(1.05-6.81)^{*}$ & 52 & 33 & $0.9(0.58-1.39)$ & $0.5(0.17-1.32)$ \\
\hline$<18$ & 7 & 10 & $1.8(0.87-3.8)$ & $1.3(0.41-3.9)$ & 4 & 11 & $0.8(0.46-0.99)^{*}$ & $0.6(0.29-1.36)$ \\
\hline \multicolumn{9}{|l|}{ Education } \\
\hline Level I & 20 & 15 & $1.3(1.22-4.06)^{*}$ & $3.1(1.66-5.67)^{*}$ & 13 & 22 & $0.85(0.45-1.59)$ & $0.57(0.20-1.59)$ \\
\hline Level II & 25 & 10 & $0.8(0.38-1.44)$ & $0.6(0.19-1.61)$ & 21 & 14 & $1.9(1.49-4.79)^{*}$ & $0.92(0.36-2.40)$ \\
\hline Level III & 36 & 22 & $0.9(0.46-2.03)$ & $0.8(0.26-2.27)$ & 32 & 26 & $1.02(0.53-1.94)$ & $1.05(0.36-2.90)$ \\
\hline Level IV & 20 & 19 & 1 & 1 & 22 & 17 & 1 & 1 \\
\hline \multicolumn{9}{|l|}{ Married/partner } \\
\hline Yes & 66 & 43 & 1 & 1 & 55 & 54 & 1 & 1 \\
\hline No & 32 & 23 & $1.8(1.51-4.07)^{*}$ & $3.6(1.8-14.37)^{*}$ & 34 & 24 & $2.5(1.24-4.93)^{*}$ & $3.3(1.21-9.13)^{* *}$ \\
\hline \multicolumn{9}{|c|}{ Childhood Residence } \\
\hline Urban & 58 & 22 & 1 & 1 & 61 & 19 & 1 & 1 \\
\hline Rural & 40 & 47 & $0.7(0.31-0.91)^{*}$ & $0.8(0.49-1.40)$ & 53 & 34 & $0.59(0.43-8.31)$ & $0.88(0.52-1.48)$ \\
\hline \multicolumn{9}{|l|}{ Proximity of family } \\
\hline Live with family & 60 & 40 & 1 & 1 & 44 & 50 & 1 & 1 \\
\hline Live with husband & 30 & 18 & $1.2(0.67-1.92)$ & $1.5(0.52-2.56)$ & 28 & 20 & $0.6(0.38-0.95)^{*}$ & $0.65(0.31-1.30)$ \\
\hline Live alone & 15 & 10 & $1.3(1.25-2.24)^{*}$ & $1.9(0.39-2.99)$ & 14 & 9 & $0.62(0.36-1.09)$ & $1.58(0.73-3.40)$ \\
\hline \multicolumn{9}{|l|}{ Family support } \\
\hline Yes & 90 & 40 & 1 & 1 & 80 & 50 & 1 & 1 \\
\hline No & 20 & 17 & $1.5(1.21-2.26)^{*}$ & $1.2(0.68-2.23)$ & 23 & 14 & $1.2(1.13-6.75)^{*}$ & $2.75(1.67-5.34)^{*}$ \\
\hline \multicolumn{9}{|l|}{ Parent live together } \\
\hline Yes & 40 & 26 & 1 & 1 & 32 & 34 & 1 & 1 \\
\hline No & 49 & 52 & $1.6(1.17-2.82)^{*}$ & $1.9(1.54-3.26)^{*}$ & 47 & 54 & $1.8(1.25-3.52)^{*}$ & $2.5(1.43-4.23)^{* *}$ \\
\hline
\end{tabular}

Note: $\mathrm{P}<0.05=*, \mathrm{P}<0.01=* * \& \mathrm{P}<0.001=* * *$

\section{Discussion}

This study has determined the magnitude of physical and sexual violence across the students' educational level. The finding of prevalence of experiencing physical violence in the current academic year was lower than previous domestic violence studies done in Butajira of $49 \%$ [7]. The difference could be attributed to the difference of age of study targets. The prevalence of sexual violence (it includes completed rape, incomplete rape and unwanted sexual contacts) was reported by $65.5 \%, 52.7 \%$ before they join technical school, and during this academic year. The current prevalence of sexual violence was reported a little greater of others studies. This figure in lined with the conducted in Addis Ababa [8]. and here indicate that there is no sexual violence free period (stage) in the lives of female students throughout the country.

The magnitude of current completed rape was $55.7 \%$ which is in contrast to the study investigated in Malaysia on paramedical students $<18 \mathrm{yrs}$ which was $8 \%$ [9]. The discrepancy might be highly exposure to services' in Malaysia beyond extra access. It is higher than the study was done in Jamaican among 450 school girls having age $13-14$ years' old which was $14 \%$ [9], this could be because our subjects are older than this age group. But it is lower to a study done in USA, Washington State of 3128 respondents of girl's grades 8,10 , and 12 which was $63 \%$ [10\&11]. This could be due to difference in socio cultural context and used huge sample size determination.

The magnitude of current incomplete rape was $71.2 \%$ which is higher comparing to a study conducted among Addis Ababa University female student which was $27.5 \%$ [12], this could be justified by the difference in their age. It is also higher when compared it with findings from Debark and Western Shewa which were $11.5 \%$ and $10 \%$ respectively [12 $\&$ 13]. This could be explained due to socio cultural difference with in the nation.

Our study has assessed some factors which are stated as contributing factors for sexual violence and physical violence in literatures. The age group among female students was significantly associated with having physical violence in this academic year, their age between 18-22 years more than two times ever had physical violence compared with others age groups this could be due to the inability to develop life skill to challenge violators once [14 \& 15]. They are victimized. Respondents who were no parents live together and have no family support more than two times risky to sexual violence compared to their parents live together and having family support at all. These findings were comparable with others studies conducted southern and western Ethiopia [7 \& 16-19]. This may point out existence of the similar backward culture context. 


\section{Strengths and Limitation of the Study}

The study used primary data from real life of students that gave insight about physical and sexual violence in technical school. The response rate of the study was high that decrease non response bias. The study was based on self-report, which is subject to made under and over reported and social desirability biases.

\section{Conclusion and Recommendations}

This study showed that prevalence of sexual violence and physical violence among technical school students is a serious problem and concern. More than half of them have reported experiences of both types of violence after joining technical school. Absence of family support and existing of parents lived alone were predictors of both physical and sexual violence.

Technical school and political leaders should collaborate to prevent and challenge gender based violence among students. Expanding and strengthening of information, education and communication activities against gender based violence in the institution. Secondary prevention activities of gender-based violence are urgently needed in technical school settings of the county context. Since it assesses experience of behavior of individuals; other researchers should be conducted a study with mixed study design that involved qualitative study.

\section{Competing Interests}

The authors declare that they have no competing interests.

\section{Acknowledgements}

The authors would like to thank Dilla University, College of Medical and Health Science, Dilla Town education office of statistics, data collectors and study participants.

\section{References}

[1] Heist Violence against women: global organizing for change. In: Edleson JL, Eisikovits ZC, eds. Future interventions with battered women and their families. Thousand Oaks, CA, Sage Publication, 2015: 7-33.

[2] Joachim J. Shaping the human rights agenda: the case of violence against women. In: Meyer MK, Prugl E, eds. Gender politics in global governance. Lanham, MD, Romans and Little field Publishers Inc., 2014: 142-160.

[3] Mayhew S, Watts C. Global rhetoric and individual realities: linking Violence against women and reproductive health In: Lee K, Buse K, Cambridge University Press, 2014: 159-180.
[4] United victimization General Assembly (2012) Declaration on the Elimination of Violence against Women A/RES/487104, 2013.

[5] Vienna Declaration and Programm of Action. United victimaization, 2015 (document A/CONF.157/23).

[6] International Conference on Population and Development (ICPD), Cairo, Egypt, United victimaization, 2014 (document A/CONF.171/13). Ms, 1994 (document A/CONF.171/13).

[7] Deyessa N, Kassaye M, Demmeke B, Taffa N. Magnitude, types and out comes ofphysical violence Against Married women in Butajira, Southern Ethiopia. Ethiopian Medical Journal 2012: 36 (3): 83-92.

[8] Terefe D and Desere M 2012. "Violence in Ethiopian School: A study of someschools in Addis Ababa.

[9] Stock. J., et al: Adolescent pregnancy and sexual risk taking among sexuallyabused girls. Family planning perspectives. 29, (5): 200-203, 227, 2012.

[10] Heist L. Lori et al. violence against women. A neglected public health issue in less developed countries, soc.sci and Med, 39 (91), 165 1179, 2014.

[11] Walker et. Al. Adult health status of women HMO member with history of childhood abuse and neglect: American journal of medicine, 54: 658-664, 2013.

[12] Tadesse S. assessments of Sexual coercion among Addis Ababa University Female Students (Master Thesis), Addis Ababa University, 2013.

[13] Worku A, and. Addisie M. Sexual Violence among female Technical school studentsin Debark, Northwest Ethiopia: East African Medical Journal, 96-99, 2013.

[14] Gossaye Y. Et al. Women's health and life events study in rural Ethiopia, Ethiopian Journal of Health Development; 17 Special Issue on BRHP: 1-44.

[15] Advocate for youth, International programs department. The World youth atrisk: Violence and its consequence. Passage, 13 (3): 1-4, 2015.

[16] Bezuayehush. and Zelalem A; Prevalence and associated factors of sexualviolence among private college female students in Bahir Dar city, North Western Ethiopia vol. 5 No. 6, June 2013.

[17] Children, youth and family welfare organization. Convection on Rights of the child, Addis Ababa, Dec. 2013.

[18] Tadiwos. S. Rape in Ethiopia. Reflection: Documentation of Panos Ethiopia: Forum on Gender. Unpublished document, 2013.

[19] Mulugeta E, Kassaye M, and Berhane Y. Prevalence and outcome of sexual violence among Technical school students in Addis Ababa and Western Showa: Eth. Me. J, 2014, 167173 . 